Electronic version of an article published as [OR Insights, 2005, Vol. 18, No.1, p. 1014]

(C) [copyright OR Society]

[http://www.palgrave-journals.com/ori/journal/v18/n1/abs/ori20053a.html] 


\title{
Annualised Hours: A Real Flexibility Tool
}

\author{
Albert Corominas; Amaia Lusa; Rafael Pastor \\ Research Institute IOC / Engineering School of Barcelona \\ Universitat Politècnica de Catalunya \\ Av. Diagonal 647, $11^{\text {th }}$ floor, 08028, Barcelona (Spain) \\ Supported by DPI2001-2176 project
}

Annualising working hours $(\mathrm{AH})$ is a mean to face the seasonal nature of the demand. AH provides much flexibility to the production system, so the company is allowed to plan the staff working time more efficiently. However, the introduction of $\mathrm{AH}$ entails new optimisation problems to solve, as is the working time planning problem. These problems should be solved in an efficient way so AH could be a real and operative flexibility tool. Mixed and integer linear programming has been shown as a very effective approach in the resolution of some real and artificial generated $\mathrm{AH}$ problems.

\section{Introduction: annualising working} hours
There are basically two ways to face the seasonal nature of the amount and the composition of the demand: to accumulate inventory (when possible) or to endow the company with enough flexibility to adjust production capacity to demand.

Volume flexibility (the quickness and ease with which plants can respond to changes in the amount and composition of the demand) can be achieved in many ways but, as it is pointed out in Slack (1991), one of the main sources of volume flexibility is the flexibility of human resources. This statement is particularly true in many service industries, since the only option they have to adapt on demand is to increase or to diminish the number of present workers in the working place. This way, these companies 
could adapt the workers' working hours or adapt the number of company workers, but this last option has usually some greater costs.

Oke (2000) carries out a survey to more than 500 manufacturing plants of the UK and analyses the applicability of some flexibility enablers: overtime, part-time, temps, job sharing, annual hours (AH), subcontracting, contract employees, varying lead times and rejecting orders. In the results, approximately $40 \%$ of the companies considers $\mathrm{AH}$ as one of the most desirable options, mainly, because of its low cost; however, it is still presented as a not very used option (around 10\%).

Annualising hours (AH) consists in distributing throughout the year the total amount of the staff's working hours, respecting some bounds and rules established in law and the collective bargaining agreement. This way, each worker can carry out different working weeks throughout the year and the company can plan the longest working weeks in high demand periods and the shortest in low demand periods. Under $\mathrm{AH}$, the harmonization between demand and capacity is a real possibility.

Although some early antecedent of $\mathrm{AH}$ can be found (e.g., in 1956 three hundred workers of Sevalco, in Avonmouth, UK, were employed on a shift system based on $\mathrm{AH}$ ), the first significant cases of $\mathrm{AH}$ date from the seventies, when some French, German and Scandinavian companies began to use this kind of contract; however, its use did not become extensive until the final eighties (Gall, 1996). In 1993, 6\% of UK workers had this type of contract, being the second most common form of non-standard working arrangement and, in 1996, the 10\% was reached (Gall, 1996). Today, $\mathrm{AH}$ hours is gaining more importance: the number of firms that are agreeing $\mathrm{AH}$ contracts is rising more and more.

The flexibility obtained with $\mathrm{AH}$ is highly desirable for service firms as well as for manufacturing companies: the costs due to lack of capacity (overtime, temporary workers, lost 
demand and inventory) can be decreased, product and service quality and productivity can be increased and, therefore, competitiveness. The main inconvenience of $\mathrm{AH}$ is that the realization of irregular working weeks could imply a worsening of the workers' working conditions, not accepted neither by workers neither by unions unless some kind of compensation is offered by the company.

The most important inconveniences that workers may find under $\mathrm{AH}$ are: difficulty to manage their free time; and salary decrease (due to the decrease of overtime). Fortunately, some compensations could be negotiated: reduction of the annual working time (as in France does Aubry II or “35 hours" law, establishing a working time reduction, without salary reduction, and permitting its irregular distribution); salary improvements; reduction of firing probability (fires in low demand periods are avoided); more holidays, more consecutive days without working; etc. Furthermore, some bounds and rules are established (in law and in the collective bargaining or firm agreement) in order to avoid worker overload in high demand periods.

Under $\mathrm{AH}$ it is essential to plan working time throughout the year (working weeks, overtime, temporary workers, etc.) with an adequate optimisation procedure. On the one hand, the procedure must give working time planning complying with the established bounds and rules: an optimal solution can be difficult to find. On the other hand, the obtained working time allows the firm to quantify how costs diminish when working hours are annualised and then to evaluate the convenience of introducing an $\mathrm{AH}$ scheme. Furthermore, planning working time, considering different annualised hours conditions (for example, different annual number of working hours and different levels of weekly flexibility), provides the company and the workers with quantitative information that should be essential for a collective bargaining process. Testing several situations, the company could evaluate 
the trade-off between the weekly flexibility accepted by workers and the reduction in annual working time or the economic compensation oferred by the company in exchange for the worsening in the working conditions.

\section{Characteristics of AH problems.}

There is a great variety of $\mathrm{AH}$ problems, depending on some characteristics that should be studied in order to design efficient solving procedures. The study of real cases and the analysis of the normative mark (laws and collective bargaining agreements) has allowed us to identify the basic characteristics of $\mathrm{AH}$ problems (see Corominas et al 2002a, for more details):

Types of products. The product could be non-storable or could be storable (and non-perishable or perishable).

Nature of the productive process. The process may require the simultaneous presence of all team members (which implies that all should complete the same schedules) or may only require the direct intervention of a person (which implies that each worker can take different working hours).

Type of flexibility. Five different methods have been identified and the most relevant are the following: a) Bounded weekly working hours: every week, any number of hours between a lower and an upper bound can be planned. b) Predetermined working week types: the duration of the working week must belong to a determined list (of, e.g., 25, 35 or 45 hours). c) Flexible hour grant: workers usually carry out a regular working week, but in one year the use of a certain number of flexible hours (that have to be compensated with rest) is permitted.

Cross-trained workers. We distinguish two situations: 1) each category can perform only one type of task and each type of task is performed only by one category; 2) workers are cross-trained and can perform several types of tasks (with equal or different efficiencies). 
Conditions imposed to the solution. Among others: 1) the total annual working hours are upper bounded; 2) minimum requirements: although the system is sized to cover the whole demand, in some weeks this cannot be possible and an inferior service level can be accepted, provided that a minimum level is satisfied. 3) the average of worked hours in a certain number of consecutive weeks, $L$, should not be superior to $h_{L}$ hours/week; 4) strong weeks: in one year, and for each worker, the number of weeks in which the worked hours overcome a given value should not exceed a specific value; 5) weak weeks: in one year, and for each worker, the number of weeks in which the number of worked hours is inferior to a given value should be at least of a specific value.

Demand satisfaction. It can be considered that demand should be covered in each period (resorting if it is necessary to subcontracting or overtime) or it could be accepted that part of the demand cannot be covered (considering lost demand or differed demand).

Overtime regulation. Overtime could be permitted (at annual or weekly level and with monetary or rest compensation) or not.

Possibilities of hiring temporary personnel / subcontracting production. Sometimes it is possible to hire temporary personnel or subcontract production to take charge of the demand that cannot be covered by the staff.

Holidays. Holidays are negotiated apart from the annual working time planning or, given some rules, holiday weeks are included in the planning problem.

Solution evaluation criteria. The economic criteria are usually the most important. However, other criteria could be kept in mind: regularity of working time throughout the year (for each worker); equal distribution of overtime; suitability in the assignment of tasks to categories; etc. 
problem by means of mathematical

As it can be seen, the combination of the previous characteristics gives rise to hundreds of $\mathrm{AH}$ problems but, is there any efficient approach to solve them in an optimal way?

\section{PLM: an annualised working hours planning efficient procedure}

An instrument for solving the annualised working hours planning problem should provide the working time (e.g., in hours) of each one of the workers in each one of the periods of the planning horizon (a year or the rest of the year).

Some companies solve AH problems but they do not explain details such as the approach used or the evaluation criteria function (if there is any); then, the existing literature is very limited. For example, in Vila and Astorino (2001) an AH case is exposed: in an agricultural machinery organization, the main results have been $94 \%$ of diminishment in the overtime cost and $53 \%$ of diminishment in the use of temporary workers; they solve the programming.

We have been working in the resolution of AH problems since 1999, solving real and artificial generated cases by means of mixed and integer linear programming (MILP), which has been shown as an appropriate and efficient technique to obtain an optimal annualised working hours planning, keeping in mind the different restrictions imposed to the solution. In our experiments, very satisfactory times of resolution have been obtained for large size models (even for 500 workers), so AH appears as a real and operative tool towards flexibility.

In Corominas et al (2002b) a problem (based on a real case) of planning the staff working hours with an annual horizon in a service centre is solved: the number of weekly working hours is bounded; there are two categories of workers, and the first one is able to carry out their tasks and the tasks of the second category; demand should be covered with the possibility of resorting to overtime as well as to 
hiring temporary workers; and, besides other constraints, the solution must minimize the cost due to overtime and recruiting and then maximize the regularity of the workers' working time throughout the year. Solving times were very satisfactory for cases of realistic sizes (up to 250 workers).

We have also been working with a software engineering company, which has developed a working-hour implemented in two great French companies (a department store and a car repairing and maintenance company). To our knowledge, both implementations of annualised hours have been very satisfactory. planning software that has been

time is annualised (the working week is lower and upper bounded to 25 and 50 hours, respectively) and the total amount of annual hours is diminished $12.5 \%$ as a compensation (from 1,840 hours, corresponding to an average of 40 hours/week to 1,610 hours, corresponding to an average of 35 hours/week). To reduce the worsening in the working conditions, the average of working hours for any set of twelve consecutive working weeks is not superior to 44 hours. Comparing both figures it can be seen how capacity is used efficienty and how shortages decrease (90.8\%) even reducing the total amount of working hours.

\section{INSERT FIGURE 1 HERE}

\section{INSERT FIGURE 2 HERE}

Below, there is a comparison between before and after annualised hours: Figure 1 shows demand, capacity and shortage profiles before annualising working hours: 40 hours for each worker and working week (notice that in some weeks capacity diminishes because of workers' holidays). Figure 2 shows these profiles when working
We have also artificially generated other service and industrial cases, which we have solved by means of MILP and the results have been very satisfactory (see Corominas et al 2002c-2002d, 2003, for more details). In some of them, different models (some with up to 1,5 milions of 
variables and others with more than 35,000 binary variables and 16,000 constraints) are sequentially solved. In all cases, and in spite of the large size of the models, MILP has shown to be an efficient tool for solving these kinds of problems (this efficiency allows companies to solve several models including criteria relative to workers' working conditions in a hierarchical way).

The solutions of the solved problems show how capacity is adapted to demand when $\mathrm{AH}$ are introduced; furthermore, comparing $\mathrm{AH}$ to regular working hours it can be seen how the costs due to overtime, temporary workers, subcontracting, lost demand and, in some cases, inventory, are diminished.

\section{Conclusions}

Annual hours are a flexibility source that allows companies to adapt productive capacity to demand fluctuations, diminishing this way the costs due to lack of capacity: overtime, temporary personnel, subcontracting and inventory.

Under $\mathrm{AH}$ there are some constraints affecting working time planning that must be satisfied; if evaluation criteria have to be optimized, then an optimal solution can be quite difficult to find. Therefore, it is essential to have an efficient solving procedure so $\mathrm{AH}$ can result in a real and operative tool towards flexibility.

Mixed and integer linear programming is an appropriate optimisation approach that has been shown as very efficient in some real cases and in other artificially generated problems.

\section{For the interested reader}

Corominas A, Lusa A, Pastor R (2002a), “Characteristics and classification of the annualised working hours planning problems”. Working paper, IOC-DT-P-2002-18, Universitat Politècnica de Catalunya.

Corominas A, Lusa A, Pastor R (2002b). "Using MILP to plan 
annualised hours". Journal of the Operational Research Society, 53, 1101-1108.

Corominas A, Lusa A, Pastor R (2002c). "Planning annualised hours with a finite set of weekly working hours and joint holidays”. Working paper, IOC-DT-P-2002-16, Universitat Politècnica de Catalunya.

Corominas A, Lusa A, Pastor R (2002d). "Planning annualised hours with a finite set of weekly working hours and cross-trained workers". Working paper, IOC-DT-P-2002-22, Universitat Politècnica de Catalunya.

Corominas A, Lusa A, Pastor R (2003). "Using a MILP model to establish a framework to an annualised hours agreement”. Working paper, IOC-DT-P-2003-01, Universitat Politècnica de Catalunya.

Gall G (1996). “All year round: the growth of annual hours in Britain”. Personnel Review, 25, 3, 35-52.
Oke A (2000). “Linking human resource flexibility with manufacturing flexibility: enablers of labour capacity flexibility in manufacturing plants”. Proceedings of I World Conference on POM, Sevilla, 27 August to 1 September 2000.

Slack N (1991). The Manufacturing advantage. Mercury Books.

Vila GFE, Astorino JM (2001), “Annualized hours as a capacity planning tool in make-to-order or assemble-to-order environment: an agricultural implements company case”. Production Planning and Control, 12, 4, 388-398.

Albert Corominas is a professor of industrial engineering and operations research at the Universitat Politècnica de Catalunya (UPC). He has degrees in computer science from the Universidad Politécnica de Madrid and in engineering from the Universidad del País Vasco (UPV); his $\mathrm{PhD}$ is also from the UPV. His research activities, at the Institute of Industrial and 
Control Engineering of the UPC, are focused on modelling and solving, by means of optimisation techniques, industrial engineering problems. He is author or co-author of books and papers that have been published in EJOR, Interfaces, JORS and ORL among other journals. Dr. Corominas is a member of IIE, INFORMS, ORS, POMS and SEIO.

Amaia Lusa is an associate professor of industrial engineering and operations research at the Universitat Politècnica de Catalunya (UPC). She has a degree in industrial engineering from the UPC. She holds her PhD on manpower planning (annualised working hours planning problem). Her research activities, at the Institute of Industrial and Control Engineering of the UPC, are also focused on job evaluation.

Rafael Pastor is an associate professor of industrial engineering and operations research at the engineering school of Barcelona of the Universitat Politècnica de Catalunya (UPC). Previously, he worked as a product production manager for Revlon. Dr. Pastor holds his $\mathrm{PhD}$ in industrial engineering and a Master's Degree in Logistics’ Organization. His research is focused on the use of a variety of combinatorial optimization techniques in order to model and solve real-world applications in production, scheduling and manpower planning. 


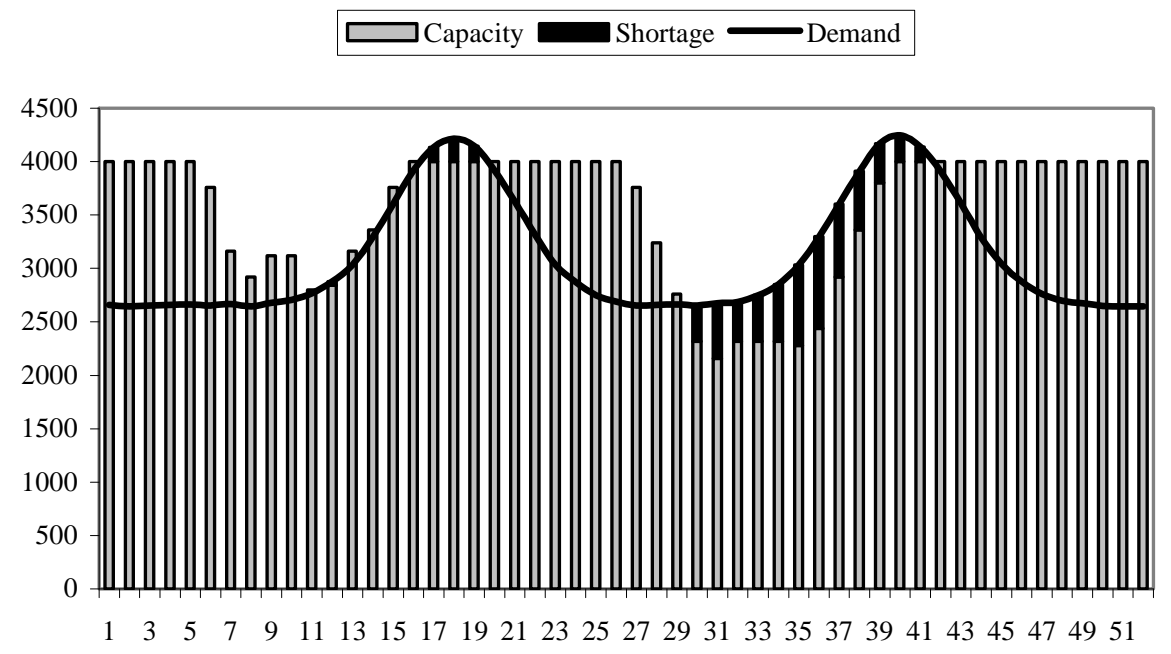

Figure 1: Demand, capacity and shortage profile before annualising hours (1,840 hours/year; 40 hours/week). 


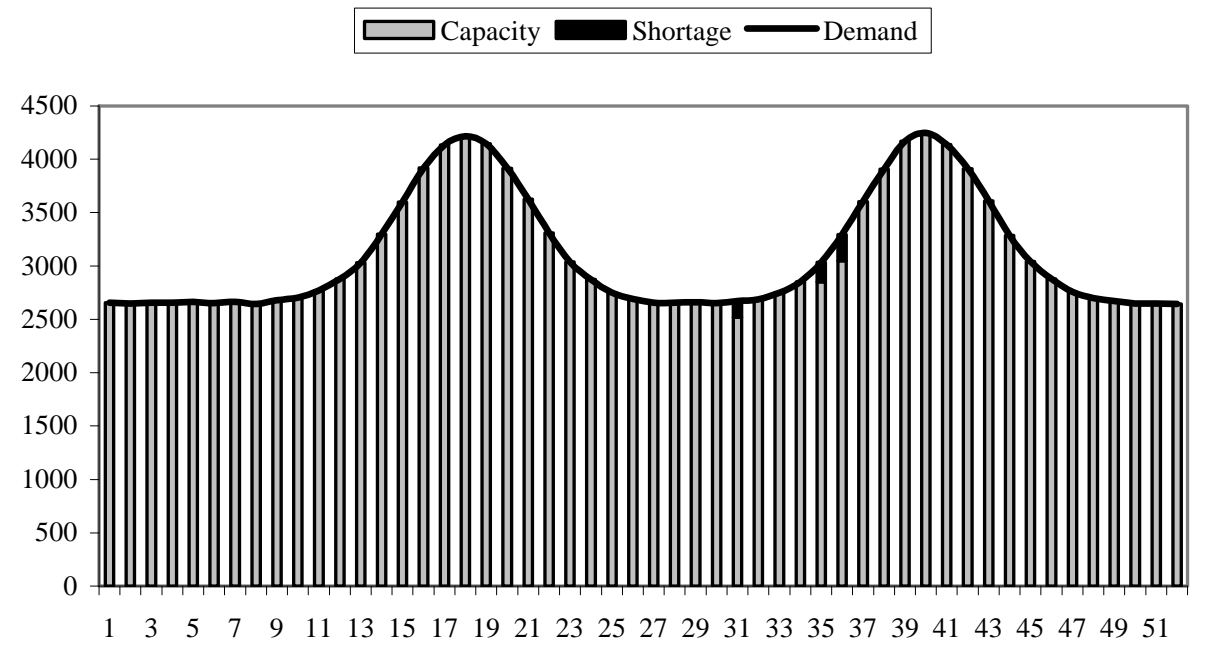

Figure 2: Demand, capacity and shortage profile after annualising hours and reducing the total amount of working hours (1,610 hours/year; from 25 to 50 hours/week). 